\title{
Regional Responses of Climate in the Northwestern Pacific Ocean to Gradual Global Warming for a $\mathrm{CO}_{2}$ Quadrupling
}

\author{
Byung-Ho CHOI, Dong-Hoon KIM \\ Department of Civil and Environmental Engineering, Sungkyunkwan University, Suwon, Korea \\ and \\ Jeong-Woo KIM \\ Department of Atmospheric Sciences, Yonsei University, Seoul, Korea \\ (Manuscript received 31 May 2000, in revised form 4 September 2002)
}

\begin{abstract}
This study investigates the regional responses of a climate model to the gradual increase of atmospheric carbon dioxide at $1 \%$ per year compounded for quadrupling. Use of NCAR fully coupled Climate System Model (CSM1.2) is attempted, with special emphasis on the simulated sea-level changes in the neighbouring seas of the northwestern Pacific Ocean with an enhanced resolution. Regional warming and sea level change are higher than global changes. At the time of $\mathrm{CO}_{2}$ quadrupling, the model predicts a rise in sea level of $19 \mathrm{~cm}$ and $25 \mathrm{~cm}$ for the globe and the northwestern Pacific Ocean, respectively, while surface air temperature rises are $2.9^{\circ} \mathrm{C}$ and $3.0^{\circ} \mathrm{C}$ for the globe and the northwestern Pacific Ocean, respectively. Based on simulations, climate changes in the Northwestern Pacific Ocean will be more distinctive compared with the global average, mainly due to exceptionally large warming and sea level change near the entrance of the Kuroshio extension.
\end{abstract}

\section{Introduction}

Over the past 10 year or so, a number of studies have been conducted on the transient response of the coupled ocean-atmosphere system to the increase in the concentration of carbon dioxide for the global climate changes (e.g., Stouffer et al. 1989; Washington and Meehl 1989; Manabe et al. 1991; Cubasch et al. 1992; Murphy and Mitchell 1995; Stouffer and Manabe 1999). However, regional scale climate changes may be different from the global aver-

Corresponding author: Byung-Ho Choi, Department of Civil and Environmental Engineering, Sungkyunkwan University, Suwon 440-746, Korea.

E-mail: bhchoi@yurim.skku.ac.kr

(C) 2002, Meteorological Society of Japan age changes, and there is only very limited capability to estimate how various regions will respond to global climate changes and subsequent sea level response.

This study investigates the regional responses of climate in the northwestern Pacific Ocean to gradual global warming for a $\mathrm{CO}_{2}$ quadrupling. The NCAR (National Center for Atmospheric Research) CSM (Climate System Model) version 1.2 was chosen to simulate both global and regional climate changes, especially focusing on regional oceanic variability in the northwestern Pacific Ocean and its neighbouring seas. Enhanced spatial resolution applied to the oceanic component of the model in these regions will improve the representation of the potential regional-scale changes. The regionally-refined fully coupled global climate 


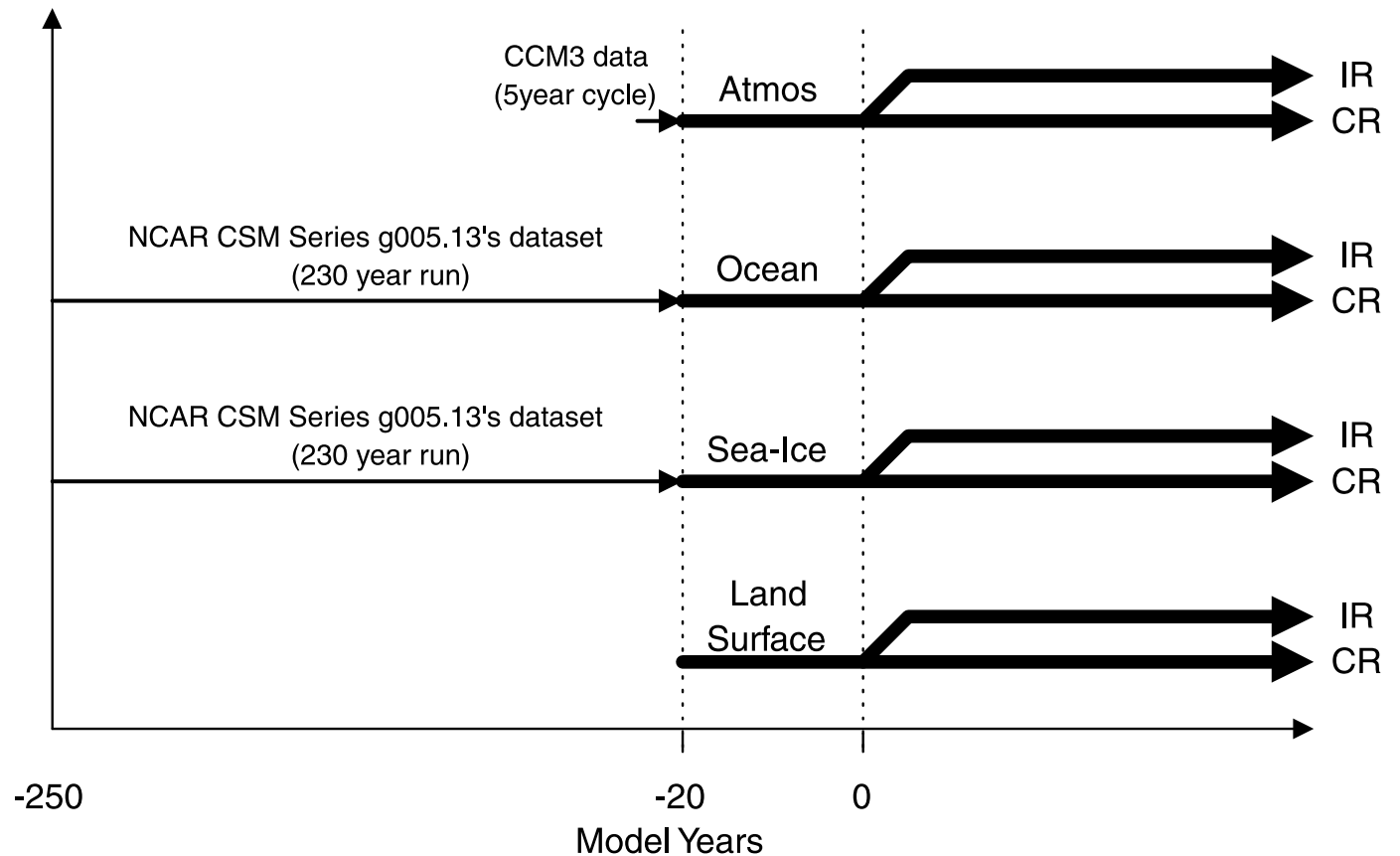

Fig. 1. The spinup, initialization, and experimental simulations procedure. g005.13 means $13^{\text {th }}$ case dataset of $5^{\text {th }}$ simulation in G-series (ice+ocean spinup run with climatological atmos+land models) by NCAR CSM.

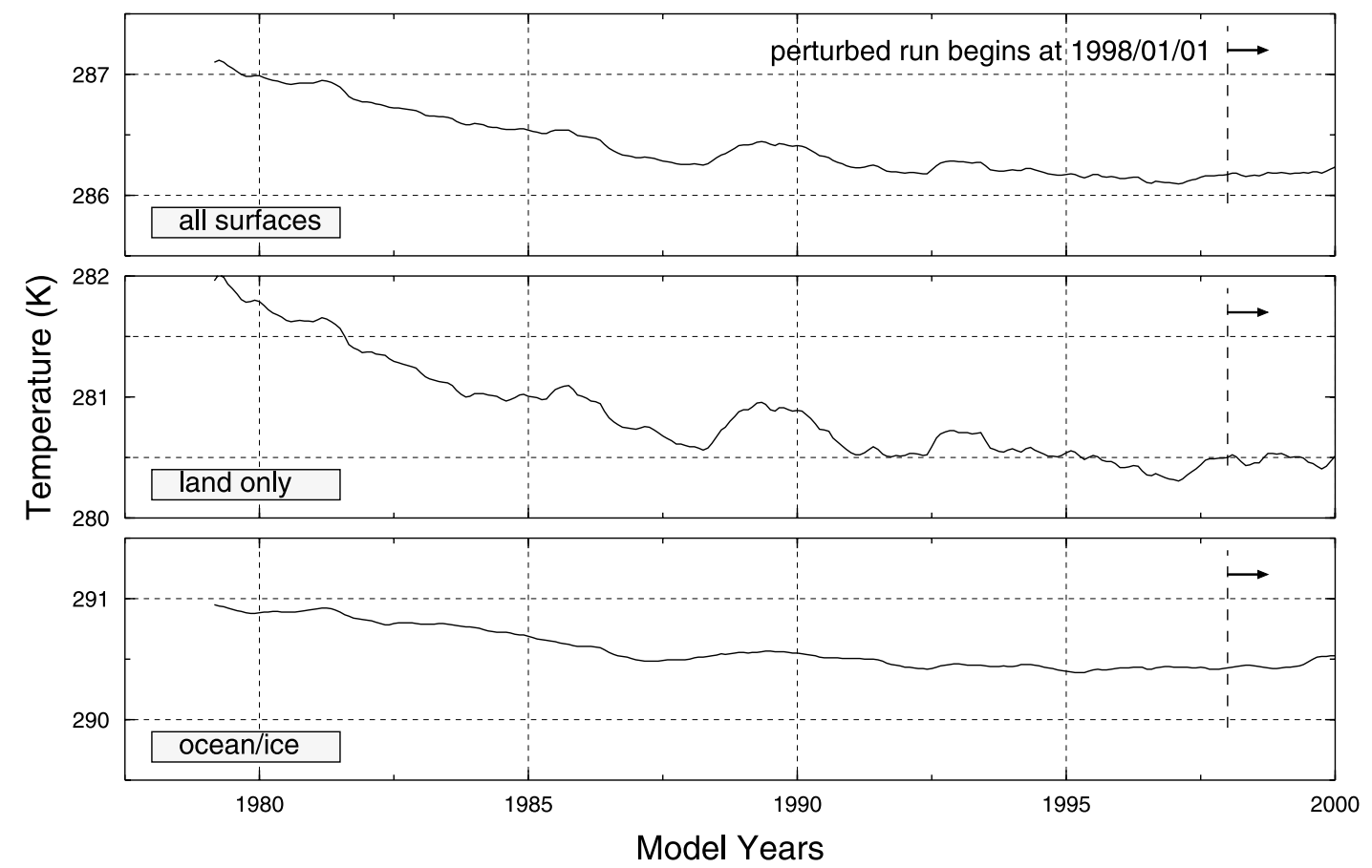

Fig. 2. Time series of 12-month running means of monthly averaged global mean surface air temperature during the initialization procedure: globally averaged over all surfaces (upper), over land only (middle), and over ocean and sea ice (lower). 

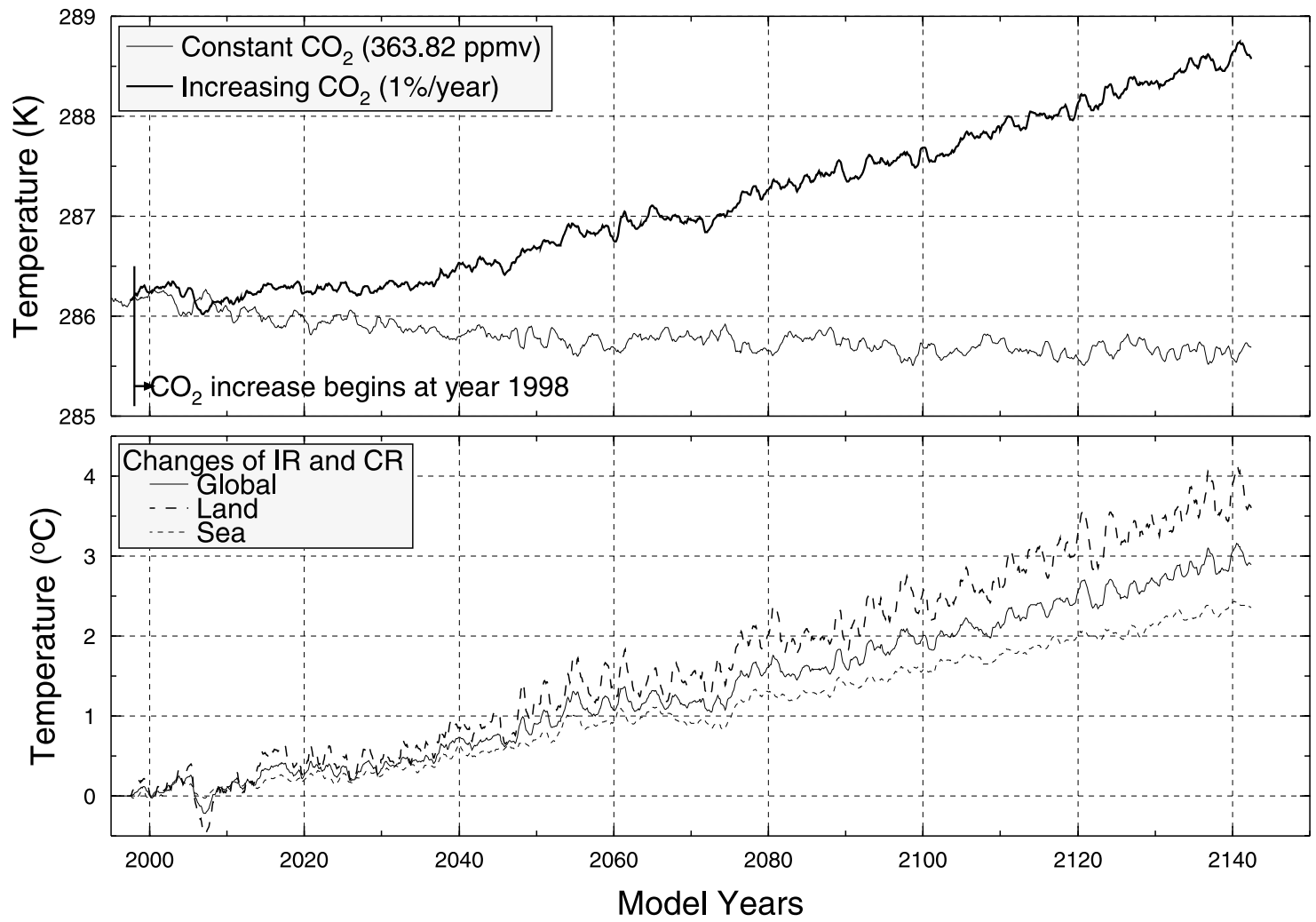

Fig. 3. 12-month running means of monthly averaged global mean surface air temperature.

system model was run for 145 years (quadruples at year 140) with averaged $\mathrm{CO}_{2}$ concentration for 1997 (Control Run, CR) and with $\mathrm{CO}_{2}$ increasing (Increasing Run, IR) at $1 \%$ per year compounded without flux correction. Indirect methods are used to estimate sea level changes because the ocean model uses a rigidlid approximation.

\section{Coupled model and experiments}

Only a brief description of the model structure is given here. For a more detailed description see Boville and Gent (1998). A comprehensive configuration of the model is composed of four basic system components: atmosphere, ocean, sea ice, and land surface, communicating with one another with a flux coupler that uses MPI (Message Passing Interface) parallel scheme. The NCAR CSM was designed and implemented for parallel computation on the CRAY supercomputer machines. We modified and ported these components so that they could be run on a COMPAQ's Alpha workstation for this study.

Atmospheric processes are simulated by the NCAR Community Climate Model version 3.3 (CCM3), which is described in Kiehl et al. (1998a), Kiehl et al. (1998b), Hack et al. (1998), Hurrel et al. (1998), and Briegleb and Bromwich (1998a; 1998b). The horizontal resolution of the atmospheric model is T31 and there are 18 unevenly spaced hybrid sigma-pressure levels in the vertical.

The oceanic component of the model is the NCAR CSM Ocean Model (NCOM) version 1.4 (Gent et al. 1998), based on the GFDL (Geophysical Fluid Dynamic Laboratory) MOM1.1 (Bryan 1969; Cox 1984; Pacanowski et al. 1991; Pacanowski et al. 1993) global oceanic general circulation model with substantial modifications, including improved mesoscale tracer transport, boundary layer mixing, and surface forcing. The resolution of the ocean model varies zonally from $0.6^{\circ}$ to $3.6^{\circ}$ and meridionally from $0.9^{\circ}$ to $3.45^{\circ}$. The longitudinal and latitudinal resolutions near the Korean Penin- 

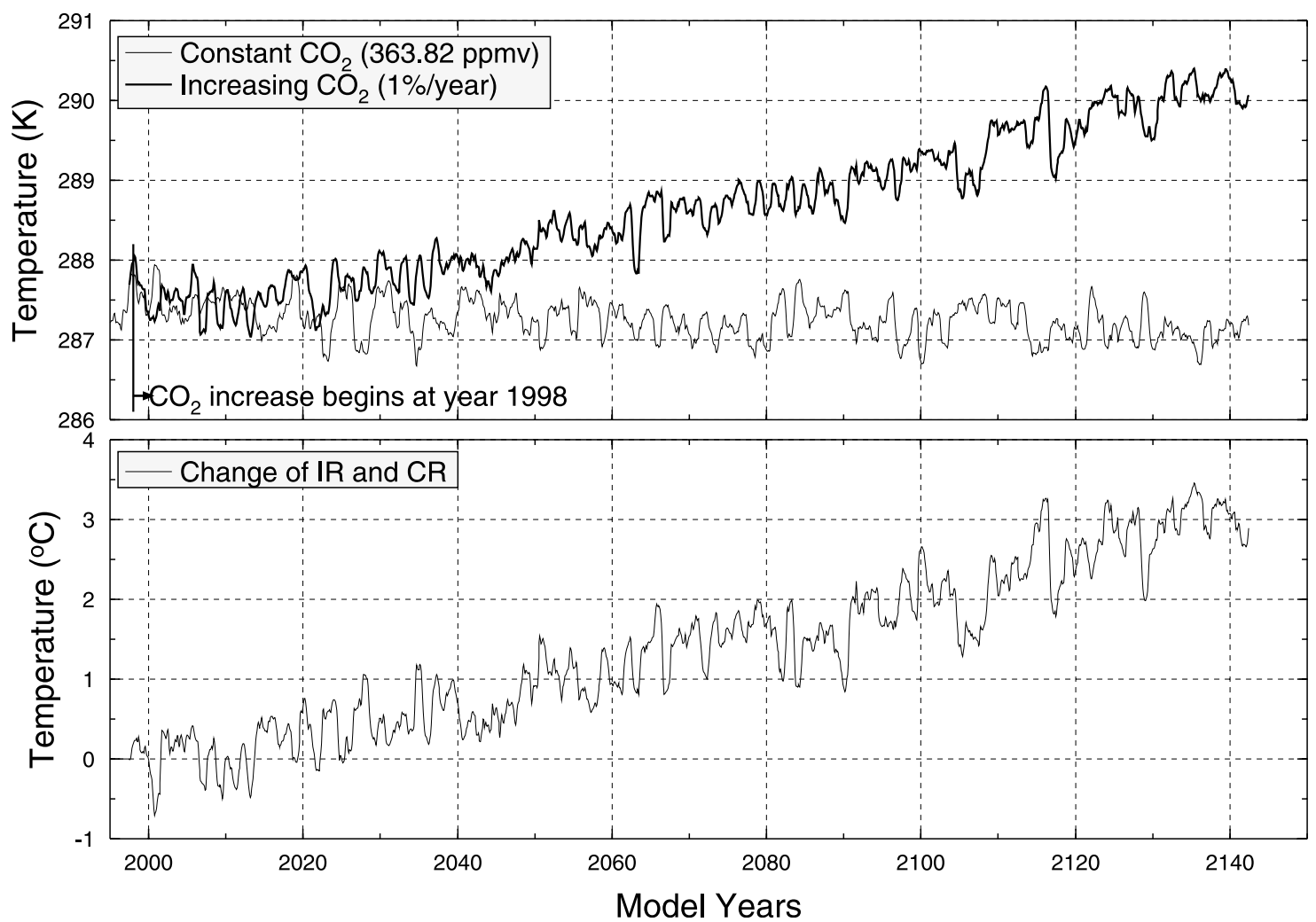

Fig. 4. 12-month running means of monthly averaged regional mean surface air temperature in the northwestern Pacific Ocean.

sula are $0.6^{\circ}$ and $0.9^{\circ}$, respectively. Total number of vertical levels is 25 . We used unequal time steps for integration of momentum and tracer equations to avoid the road block of computing time for full ocean simulations with high resolution. Our simulation with this method showed that the results of ocean and atmosphere generally agreed with observations, and predicted surface air temperature rise agreed with NCAR CSM simulations (Kim 1998).

The sea ice component is included using the CSM Sea Ice Model (CSIM2.2.6) of Bettge et al. (1996) and Weatherly et al. (1998).

The land surface component is the Land Surface Model (LSM v1.1) of Bonan (1996; 1998), which was recently developed for use within the CCM3 atmospheric model.

Initial values for carbon dioxide concentration $\left(\mathrm{CO}_{2}\right)$ was set at $363.82 \mathrm{ppmv}$, based on averaged concentration for 1997 provided by the Mauna Loa Observatory (Keeling and
Whorf 1998). $\mathrm{CO}_{2}$ value is updated monthly, with a compound rate of $1 \% / \mathrm{yr}$, divided by 12 in the Increasing Run. Monthly ozone volume mixing ratios derived by Chervin (1986) from analyses of Dütch (1978) are linearly interpolated to obtain values every 12 hours.

To perform relatively drift-free coupled simulations, compatible initial states for the component models are required. The fully coupled model was initialized by a 20 -year integration with spinup datasets (c.f., Fig. 1). The spinup datasets were taken from the NCAR CSM Experimental Series datasets. The global annual mean surface air temperature during the initialization procedure shown in Fig. 2 exhibits an adjustment of $0.8 \mathrm{~K}$ over the first $5 \sim 10$ year of the simulation and are remarkably stable afterward. The initial adjustment is largely due to a $1.5 \mathrm{~K}$ decrease in the land temperatures, resulting from the fact that a generic initial condition was inadvertently used in LSM instead of the equilibrated state from the end of 

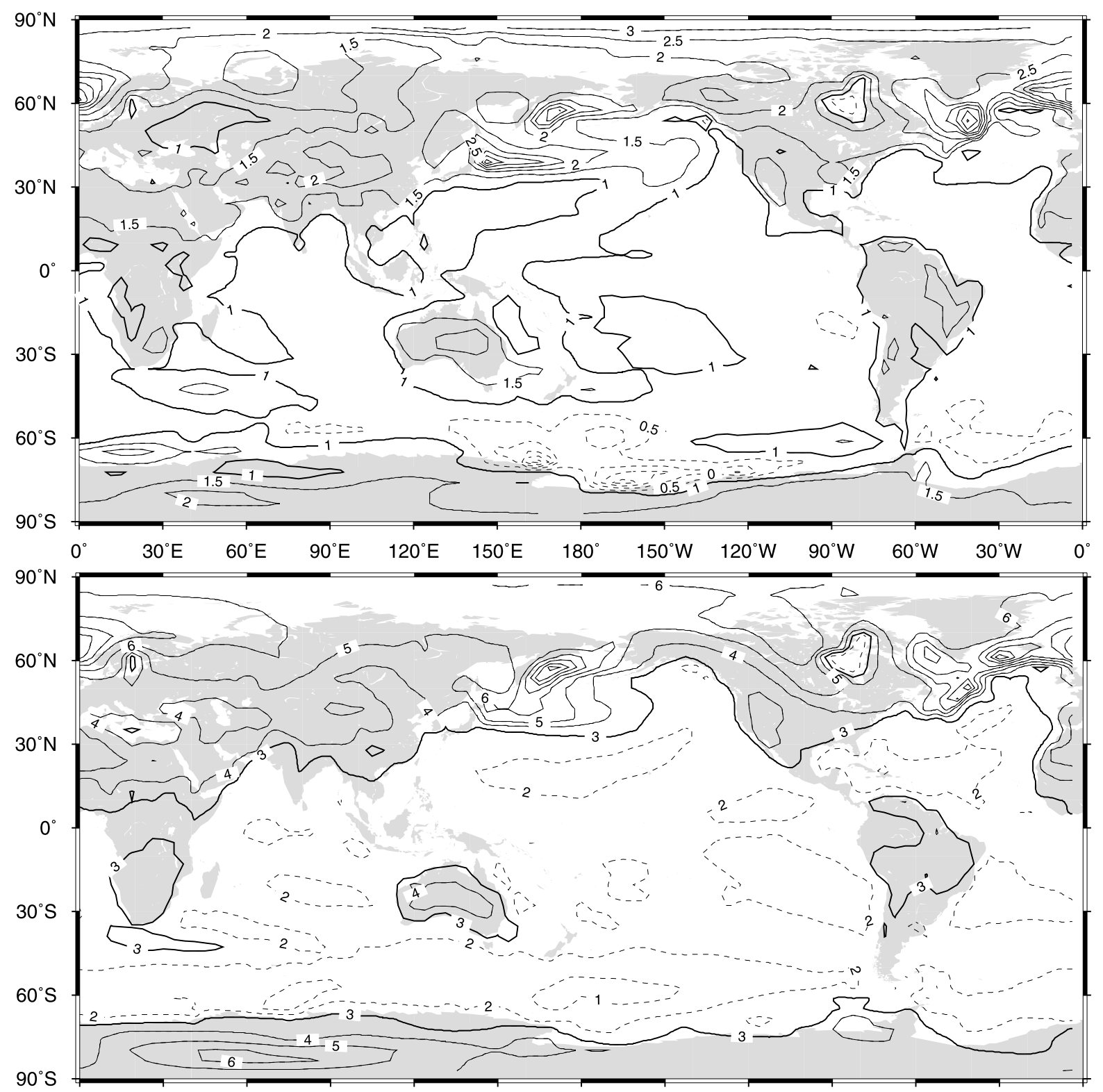

Fig. 5. The difference between 10-year averaged surface air temperature $(\mathrm{K})$ for transient $\mathrm{CO}_{2}$ experiment minus control, averaged over the years 66 75 (upper) and the years 136 145 (lower). contours at $0.5 \mathrm{~K}$ and $1.0 \mathrm{~K}$ intervals.

the CCM3/LSM1 simulation (Boville and Gent 1998). There is also an adjustment of the ocean temperatures over the first 5 10 year of the simulation, with the initial year being about $0.5 \mathrm{~K}$ warmer than any subsequent year. The coupled simulation has strong variability on multiyear timescales, but no large surface temperature trends after year ten. The volume averaged ocean potential temperature decreases by about $0.045^{\circ} \mathrm{C}$ during the initialization procedure (not shown, see Kim 1998). It seems that the deep ocean was not in a steady state at the beginning of the Control Run. The deep ocean might be expected to take several thousand years to reach equilibrium. We assume that the drift in the Control Run, and ef- 

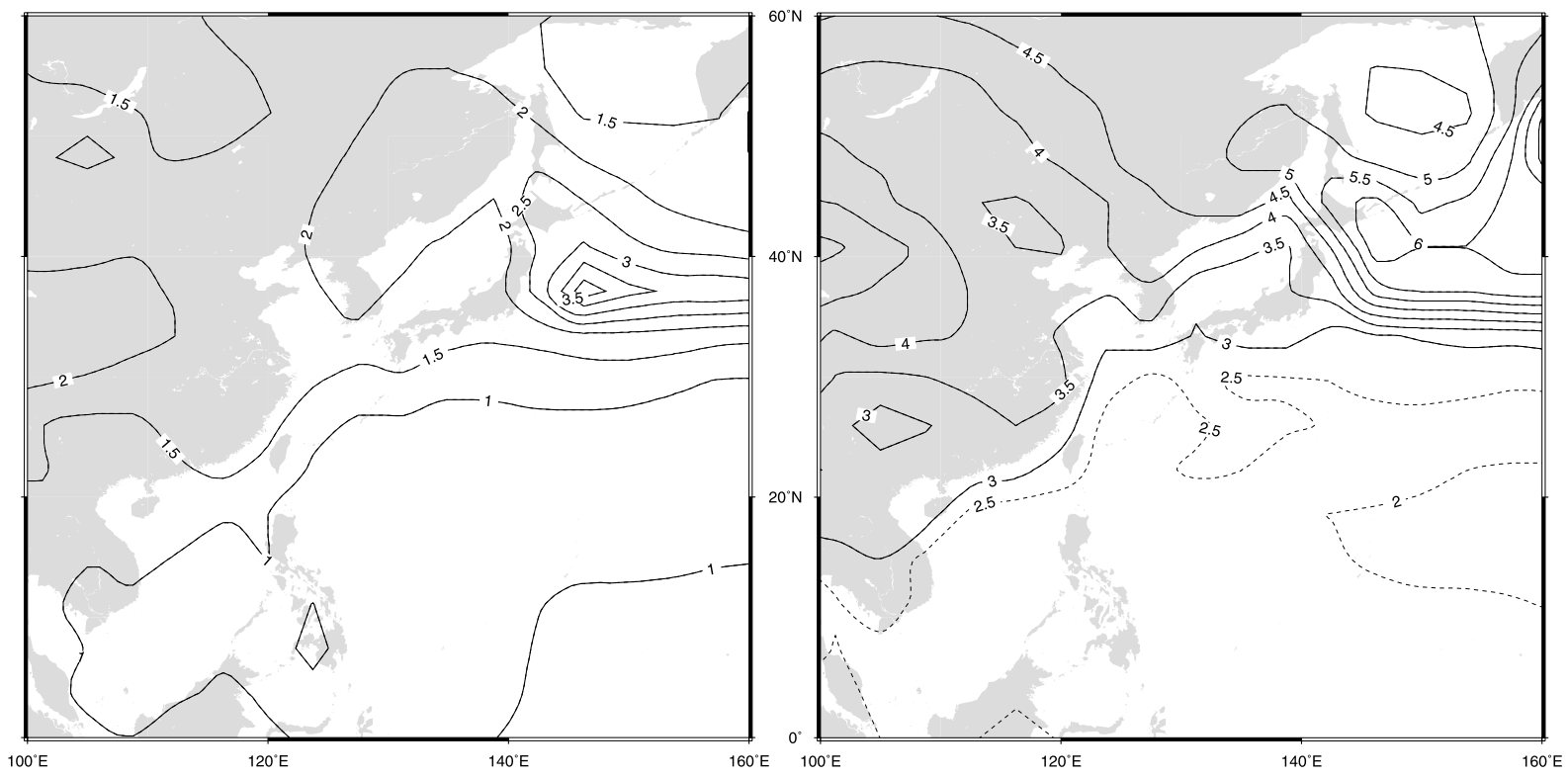

Fig. 6. same as Fig. 5 for a doubling (left) and a quadrupling (right), except for regional average (contours at $0.5 \mathrm{~K}$ intervals).

fect of climate change are combined linearly, which is likely to be reasonable since both are small (Gregory 1993). On this basis, the latter can be obtained by subtracting the Control Run from the Increasing Run.

The comparison tests were made between the observed data (ECMWF, NCEP, MSU, and ERBE), and the last 10 year averaged control integration. Kim (1998) has shown that the Control Run simulation, is a usable device, against which to compare the Increasing Run simulation (which depicts the effects of global warming).

\section{Surface air temperature}

By the 70th year, the global mean surface air temperature was increased by $1.2^{\circ} \mathrm{C}$, which lies slightly lower than other coupled models (IPCC 1996) (Fig. 3). This change is agreeable with the estimated value of about $1.25^{\circ} \mathrm{C}$ by NCAR CSM-1 (http://www.cgd.ucar.edu/csm/ experiments /b006). During the quadrupling experiments, the global mean surface air temperature increases by about $2.9^{\circ} \mathrm{C}$.

Figure 4 shows the result in the northwestern Pacific Ocean covering the region of $100^{\circ} \mathrm{E} \sim 160^{\circ} \mathrm{E}$, and $0^{\circ} \mathrm{N} \sim 60^{\circ} \mathrm{N}$, for the regional mean surface air temperature. The changes are about $1.5^{\circ} \mathrm{C}$, and $3.0^{\circ} \mathrm{C}$, for a doubling and a quadrupling, respectively.

In Fig. 5, the increase of surface air temperature tends to be larger over continents than oceans. This contrast is mainly due to the amount of moisture available for evaporative cooling over the land is limited at some locations, but over the ocean it is not (Manabe et al. 1992).

The changes of surface air temperature are particularly slow over the Circumpolar Ocean of the Southern Hemisphere, where the vertical mixing of water penetrates very deeply over a wide area. A notable difference is the hemispheric asymmetry in warming, whereby the warming is larger in the northern hemisphere than in the southern hemisphere. This asymmetry in the fully-coupled model results from the more vigorous vertical mixing between the surface and deep waters of the Southern Ocean, and is a general feature of fully-coupled simulations.

Variations of surface air temperature in and around the northwestern Pacific Ocean is shown in Fig. 6. Temperature increase above the continental land mass is higher than that of the oceans. There is an exceptionally large warming-over $3^{\circ} \mathrm{C}$ and $5^{\circ} \mathrm{C}$ for a doubling and 


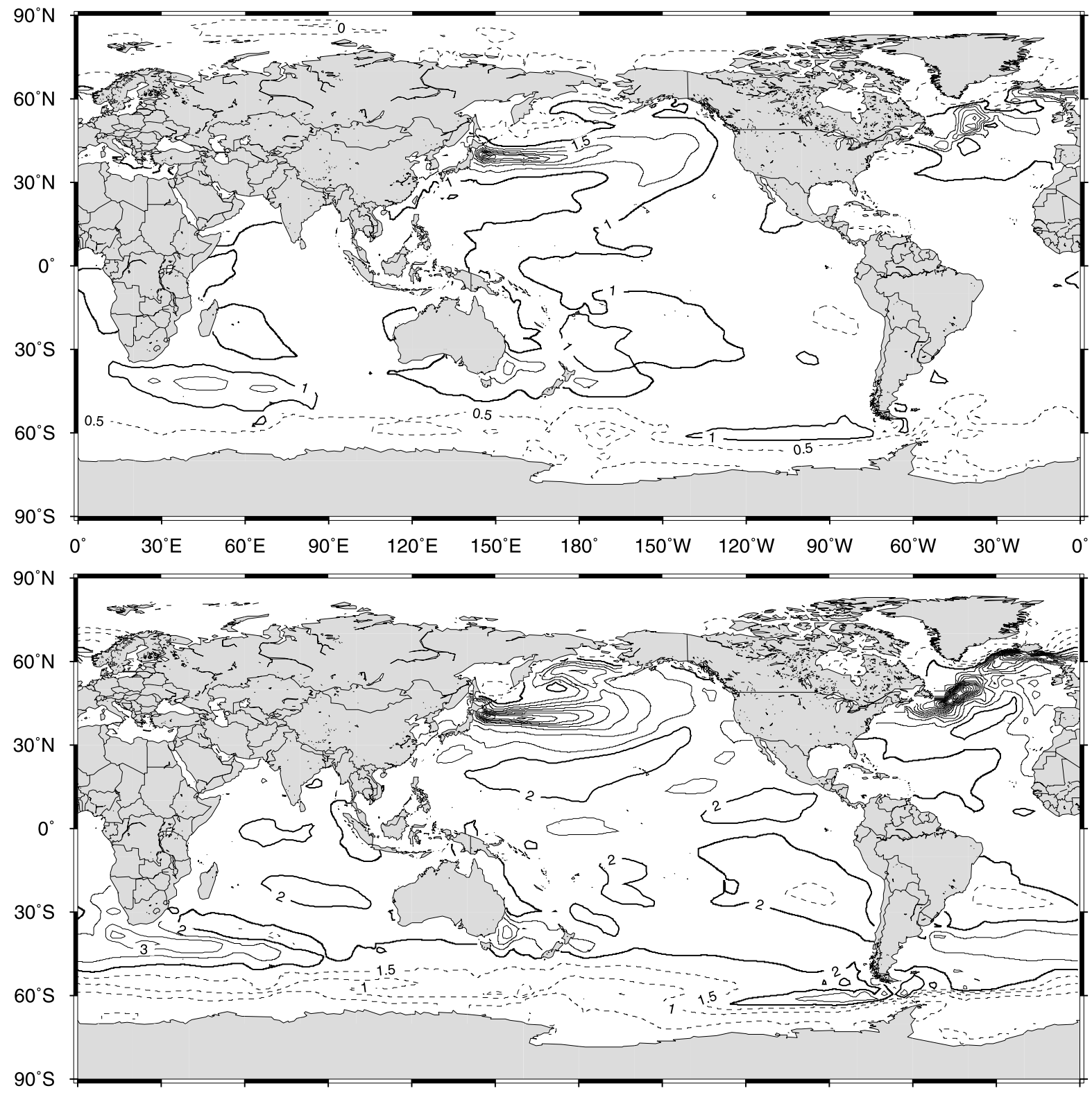

Fig. 7. The difference between 10-year averaged ocean surface temperature $\left({ }^{\circ} \mathrm{C}\right)$ over the year 66 75 (upper) and the years 136 145 (lower) are shown, transient $\mathrm{CO}_{2}$ experiment minus control (contours at $0.5^{\circ} \mathrm{C}$ intervals).

a quadrupling, respectively-near Kuroshio's separation area by the northward expansion of the separation area.

\section{Sea surface temperature and salinity}

In oceanic regions of high latitudes, where heat penetrates very deeply by mixing, both surface air temperature and sea surface tem- perature hardly changed (Figs. 5 and 7). For example, the change of sea surface temperature for a quadrupling was under $1.5^{\circ} \mathrm{C}$ over the Circumpolar Ocean of the Southern Hemisphere.

Increase of sea surface temperature was significantly different from that of surface air temperature, partly due to the existence of sea 

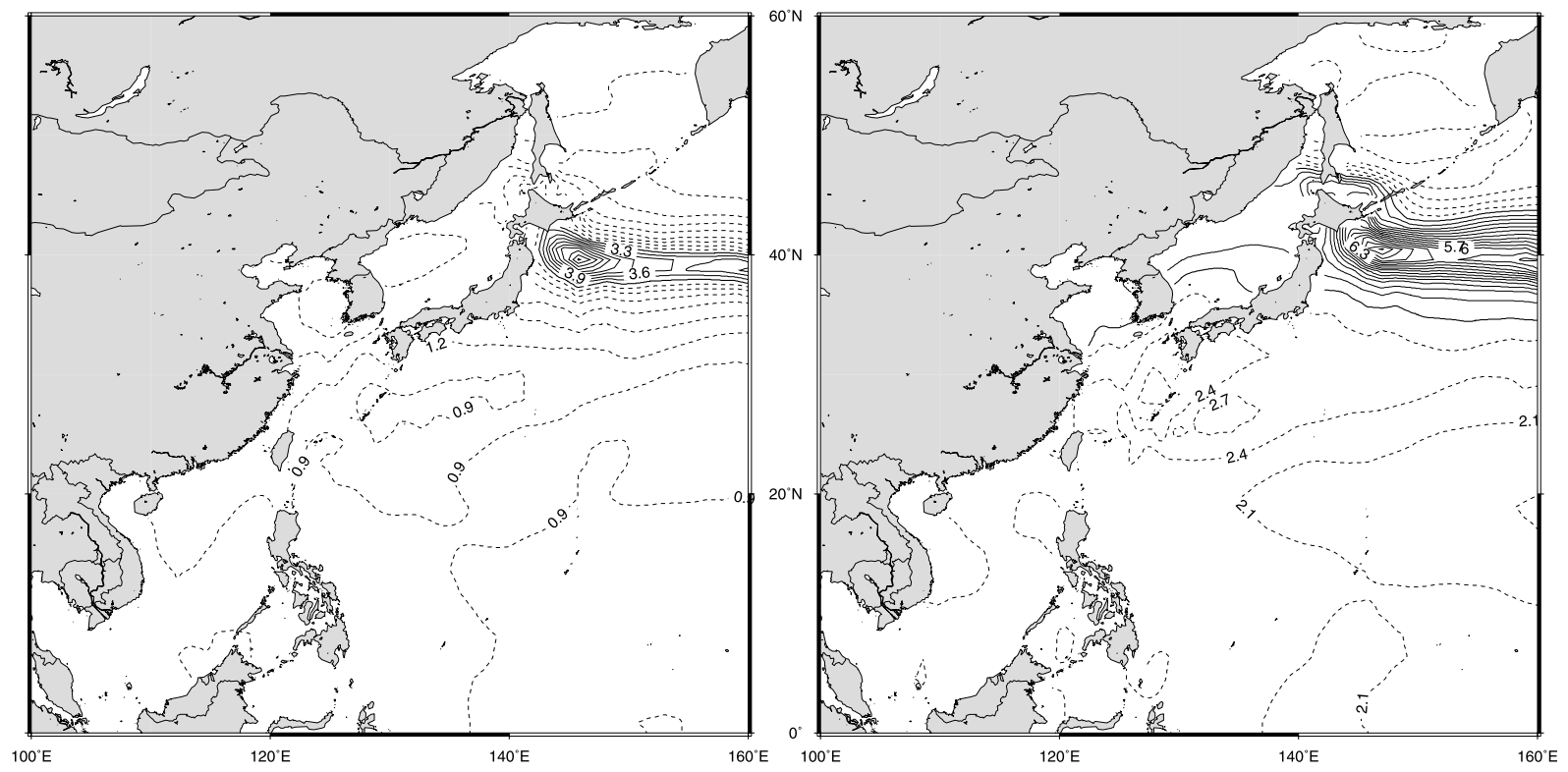

Fig. 8. same as Fig. 7 for a doubling (left) and a quadrupling (right), except for regional average (contours at interval $0.3^{\circ} \mathrm{C}$ ).

ice, which reduces heat exchange between the water and its overlying air. Over the Arctic Ocean, where the vertical mixing was small due to the existence of an intense halocline, the increase of sea surface temperature was also small, because the remaining sea ice keeps the surface water temperature near the freezing point (Manabe and Stouffer 1994).

Heating anomalies are the greatest in subpolar latitudes, especially of the Northern Hemisphere. This leads to a weakening of the ocean thermohaline circulation. The thermohaline circulation redistributes heat within the ocean from high latitudes toward the equator, and cause a more uniform sea level rise than would occur otherwise. In polar areas, sea ice covering the sea water seems to inhibit a rise in temperature.

Figure 8 presents sea surface temperature difference in the northwestern Pacific Ocean at the time of $\mathrm{CO}_{2}$ doubling, and $\mathrm{CO}_{2}$ quadrupling. A higher rise in temperature is noticeable near Kuroshio's separation point, and in the region covering a wide area centered around $40^{\circ} \mathrm{N}$ latitude. Striking temperature changes in the Kuroshio separation area is caused by the northward expansion of the separation area, due to global warming.
The main feature of the salinity change is a tendency for salinity to increase in the middle latitudes, and to decrease in polar regions. Figure 9 clearly indicates a marked reduction of surface salinity in high latitudes of both hemispheres, which results from the increased supply of fresh water. The reduction is particulary pronounced over the Arctic Ocean, and northern North Atlantic. Higher changes in surface salinity is noticeable near Kuroshio's separation point, caused by the northward expansion of the separation area (Fig. 10).

\section{Sea level change}

Sea level is not explicitly predicted by the ocean model, which uses a rigid-lid approximation to filter out fast-moving external gravity waves. In this study, we have used a traditional method to estimate sea level patterns, which is to assume that surface pressure patterns are entirely compensated by density changes within the upper part of the water column, and also it assume that the timescale of the present experiment is much shorter than reaching thermodynamic equilibrium in the deep layers of the ocean. For estimation of global coverage, the dynamic topography method, with 1000 meter as a reference depth, is used. Although 

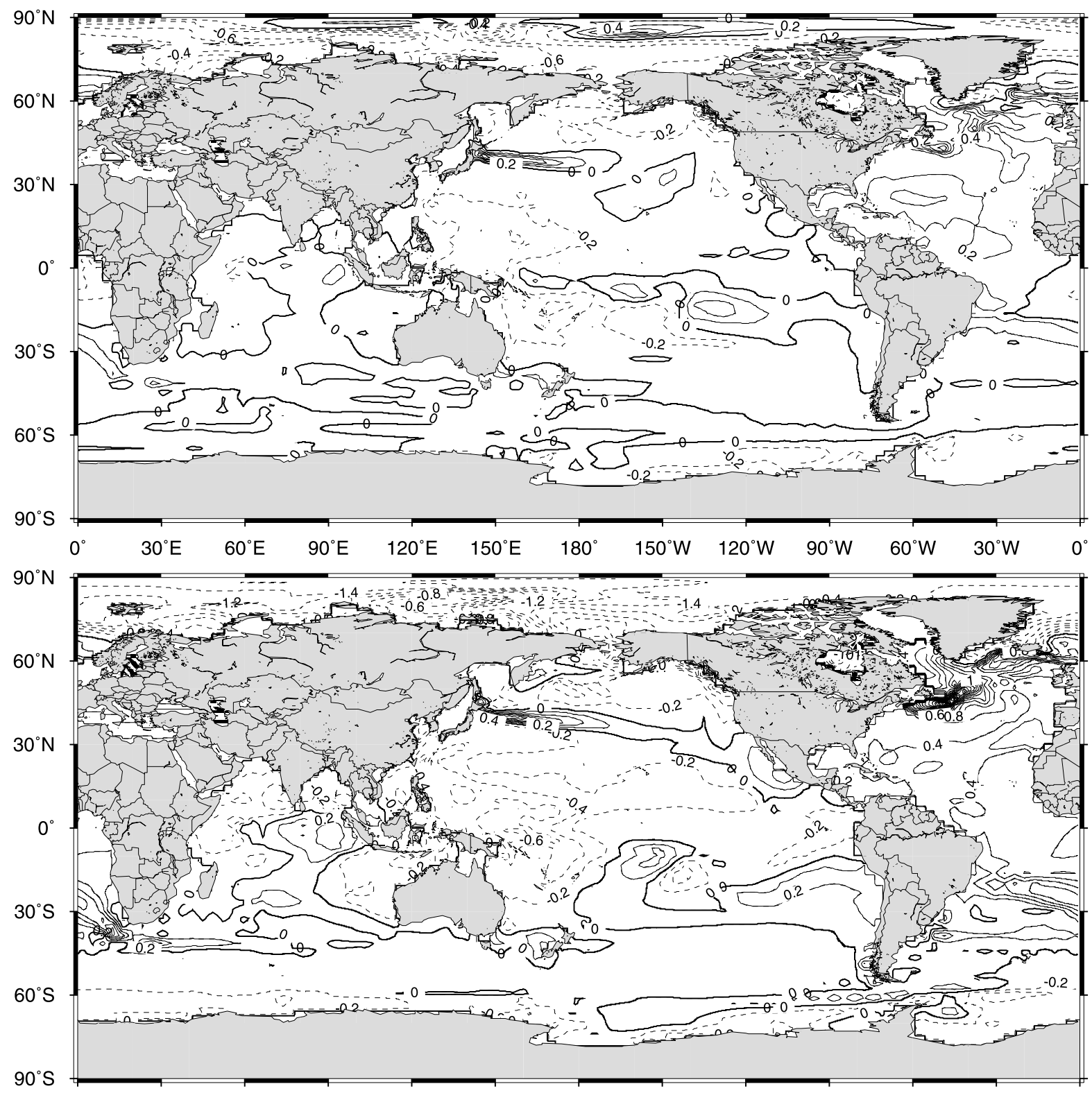

Fig. 9. The difference of a decadal averaged ocean surface (6 meter) salinity ( $\mathrm{psu}$ ), averaged over the years 66 75 (upper) and the years 136 145 (lower), are shown (contours at 0.2 psu intervals).

the changes below 1000 meter may be important in a few places, the water warms only within a few hundred meters of the surface over most of the ocean surface (Stouffer and Manabe 1999), and no noticeable difference is found between the calculations with 1000 meter, and 2000 meter reference level in our simulation.

As described in Gregory (1993), Bryan (1996), and Motoi et al. (1996), Fig. 11 shows small sea level rises in the eastern equatorial Pacific and in the circumpolar area of Antarctica. It shows that the sea level rise in the Southern Ocean is only $2 \sim 6 \mathrm{~cm}$ and $6 \sim 10 \mathrm{~cm}$ for a $\mathrm{CO}_{2}$ doubling and a $\mathrm{CO}_{2}$ quadrupling, while it is over $8 \mathrm{~cm}$ and $20 \mathrm{~cm}$ for a $\mathrm{CO}_{2}$ doubling and a $\mathrm{CO}_{2}$ quadrupling in many places north of the Circumpolar Current in the Pacific and Indian Oceans, 

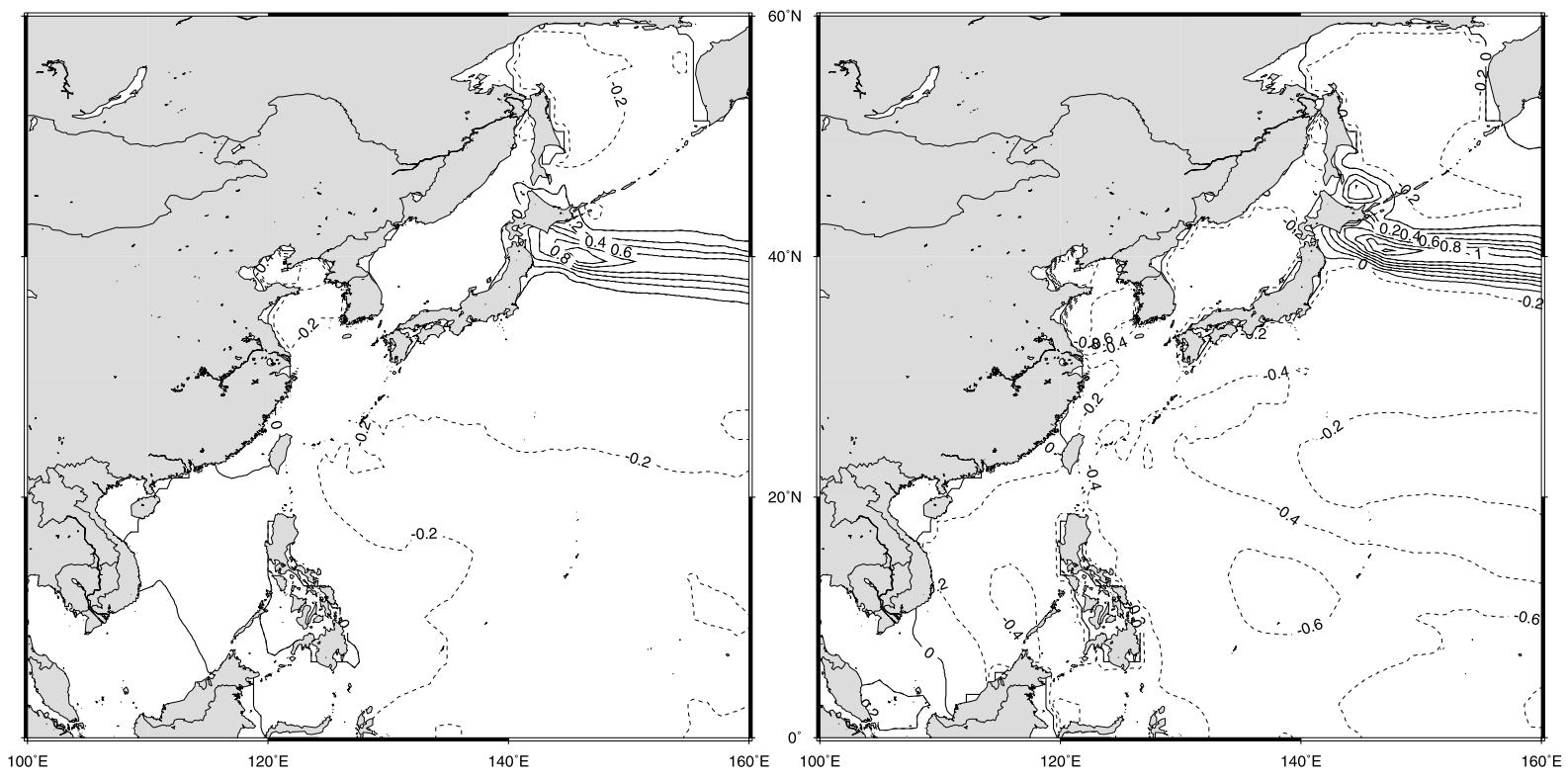

Fig. 10. same as Fig. 9 for a doubling (left) and a quadrupling (right), except for regional average (contours as 0.2 psu intervals).

respectively. There is a rather sharp gradient of the sea level rise at latitudes around Antarctica.

Figure 12 shows that Kuroshio's separation point, east of Japan, provides about $20 \sim 25 \mathrm{~cm}$, and $30 \sim 37 \mathrm{~cm}$ difference for a $\mathrm{CO}_{2}$ doubling and a $\mathrm{CO}_{2}$ quadrupling in dynamic topography, respectively. Regions with the maximum value of about $25 \mathrm{~cm}$, and $37 \mathrm{~cm}$ for a $\mathrm{CO}_{2}$ doubling, and a $\mathrm{CO}_{2}$ quadrupling appearing south of $40^{\circ} \mathrm{N}$ looks like the effect of the northward expansion of the Kuroshio separation area, respectively. Sea level rise of over $10 \mathrm{~cm}$, and over $20 \mathrm{~cm}$ for a $\mathrm{CO}_{2}$ doubling and a $\mathrm{CO}_{2}$ quadrupling, are found in the region southeast of Japan, respectively.

In the offshore areas of the Philippines, sea level rise is not that big (under $6 \mathrm{~cm}$ and under $20 \mathrm{~cm}$ for a doubling and a quadrupling, respectively) due to smaller temperature rise, and salinity changes. One of the most interesting features in Fig. 12 is the strong sea level rise due to the northward expansion of the Kuroshio seperation area. We examine this feature in more detail in Fig. 13, and Fig. 14. It shows the horizontal variations of ocean currents in the northwestern Pacific Ocean, over a doubling and a quadrupling. Areas of big changes seen near Kuroshio's separation point, due to northward expansion of the separation area. This leads to the exceptionally large warming SST and SAT.

Ten-year average sea level changes are about $7 \mathrm{~cm}$ for a $\mathrm{CO}_{2}$ doubling and about $19 \mathrm{~cm}$ for a $\mathrm{CO}_{2}$ quadrupling (Fig. 15). In Fig. 16, it is seen that ten-year average sea level changes in the northwestern Pacific Ocean are about $10 \mathrm{~cm}$ for a $\mathrm{CO}_{2}$ doubling, and about $25 \mathrm{~cm}$ for a $\mathrm{CO}_{2}$ quadrupling, indicating the higher value than the global average. Sea level changes could be much larger if the contribution of meltwater from continental ice sheets were included.

Because the deep ocean will warm much more slowly than the upper ocean, the steric rise in sea level is expected to continue for centuries after atmospheric $\mathrm{CO}_{2}$ stops increasing (Manabe and Stouffer 1994; Stouffer and Manabe 1999).

\section{Summary and discussion}

The NCAR Climate System Model, version 1.2 , has been run in fully coupled mode for 145 years $\left(\mathrm{CO}_{2}\right.$ doubles at about year 70 and $\mathrm{CO}_{2}$ quadruples at about year 140), using regionally-enhanced resolution.

Responding to a gradual increase of atmo- 


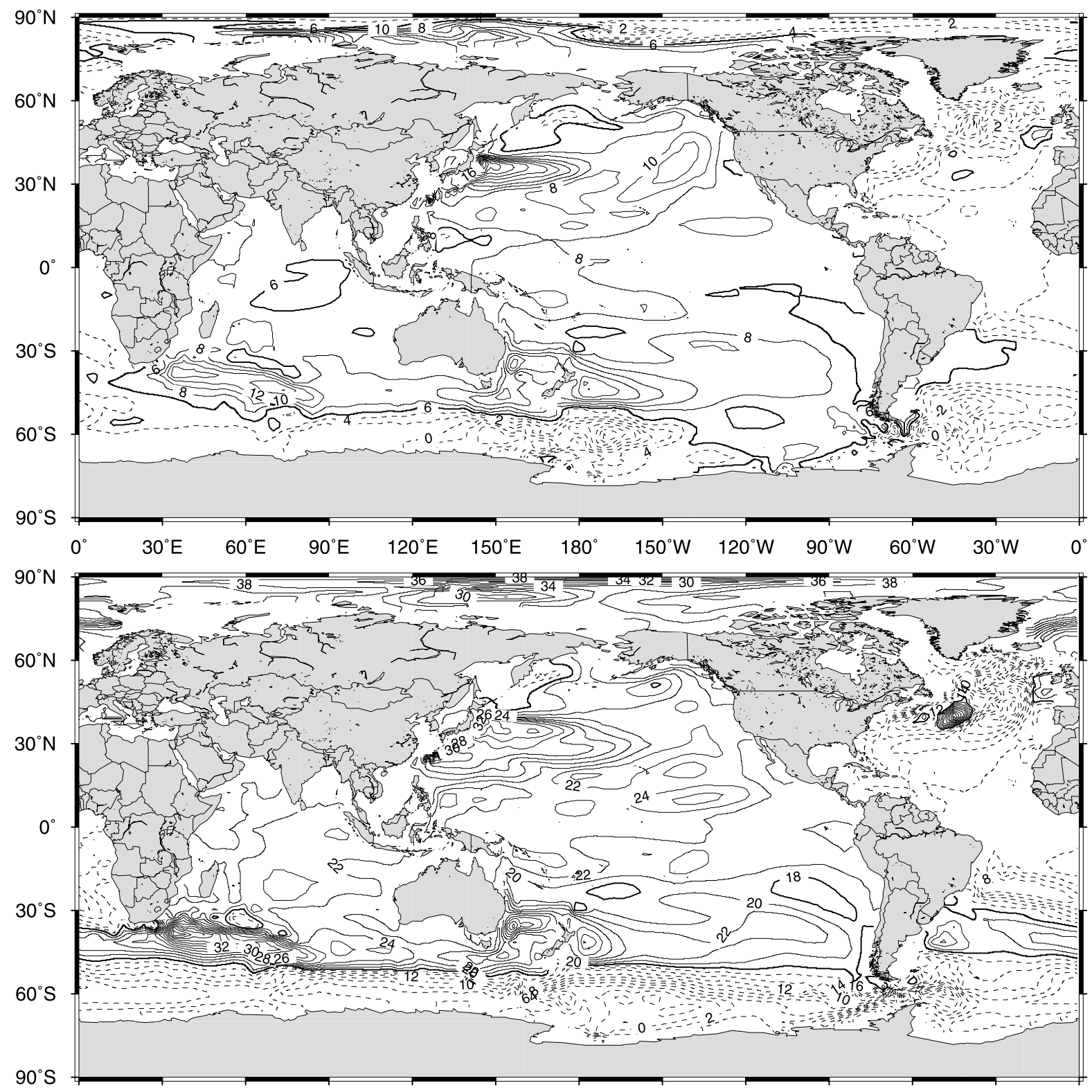

Fig. 11. The difference of a decadal averaged dynamic topography anomaly (in $\mathrm{cm}$ ) between the CR and the IR for a doubling (upper) and a quadrupling (lower) (contours at $2 \mathrm{~cm}$ intervals).

spheric carbon dioxide, the warming is largest in polar regions. The warming above the continental land mass is higher than that of the oceans. The warming is larger in the Northern Hemisphere than in the Southern Hemisphere, where the vertical mixing of water penetrates very deeply.

Regional warming, and sea level change are higher than those of the globe. At the time of
$\mathrm{CO}_{2}$ doubling, the model predicts a rise in sea level by $7 \mathrm{~cm}$ and $10 \mathrm{~cm}$ for the globe and the northwestern Pacific Ocean, respectively, while the corresponding surface air temperature rise is $1.2^{\circ} \mathrm{C}$ and $1.5^{\circ} \mathrm{C}$, respectively. During the quadrupling experiments, the global and regional mean surface air temperature increase by about $2.9^{\circ} \mathrm{C}$ and $3.0^{\circ} \mathrm{C}$, respectively. The rise of sea level, due to the thermal expansion of sea 

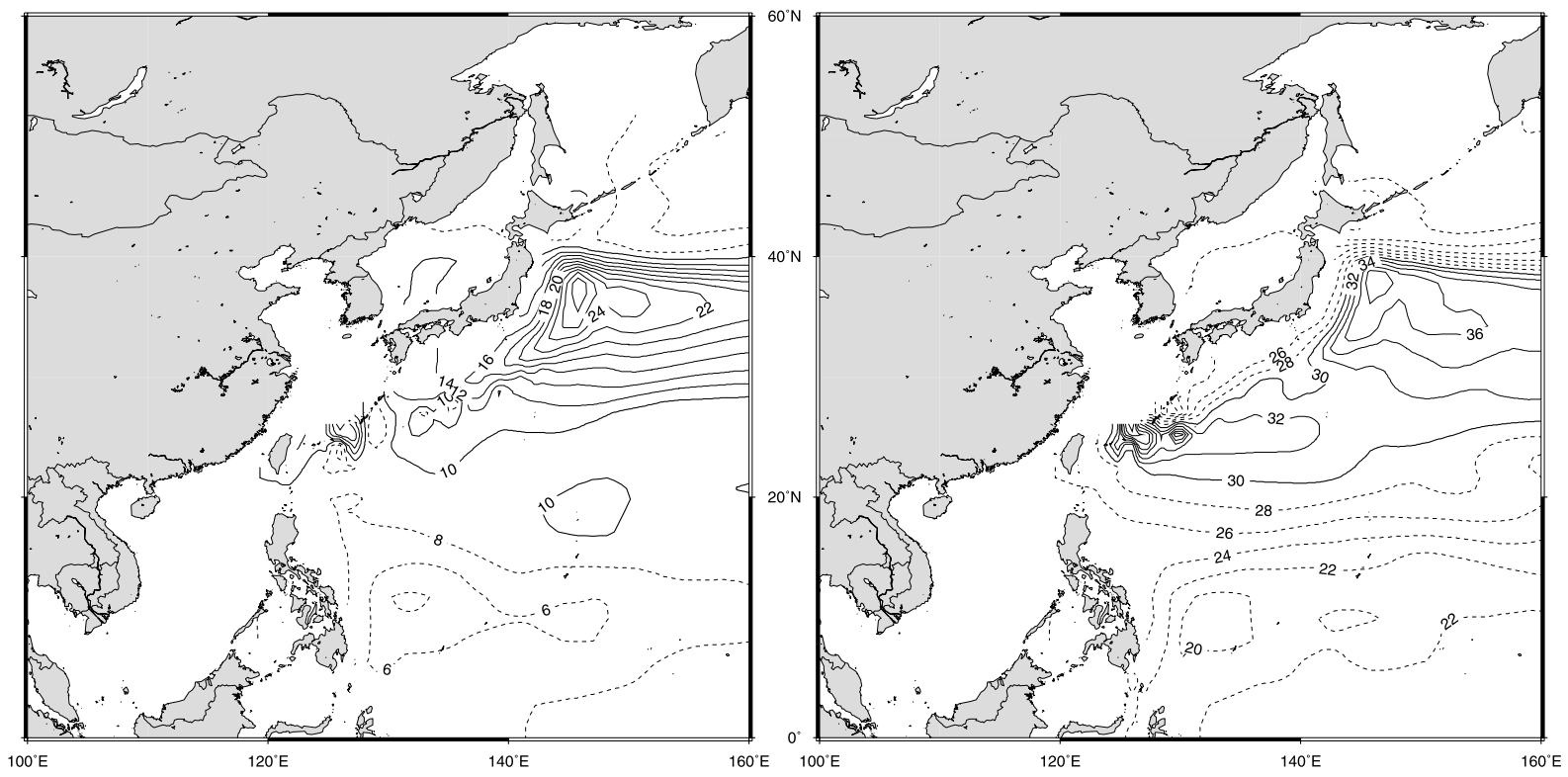

Fig. 12. A decadal year average sea level change $(\mathrm{cm})$ between the $\mathrm{CR}$ and the $\mathrm{IR}$ for a $\mathrm{CO}_{2}$ doubling (left) and a $\mathrm{CO}_{2}$ quadrupling (right) (contours at $2 \mathrm{~cm}$ intervals).
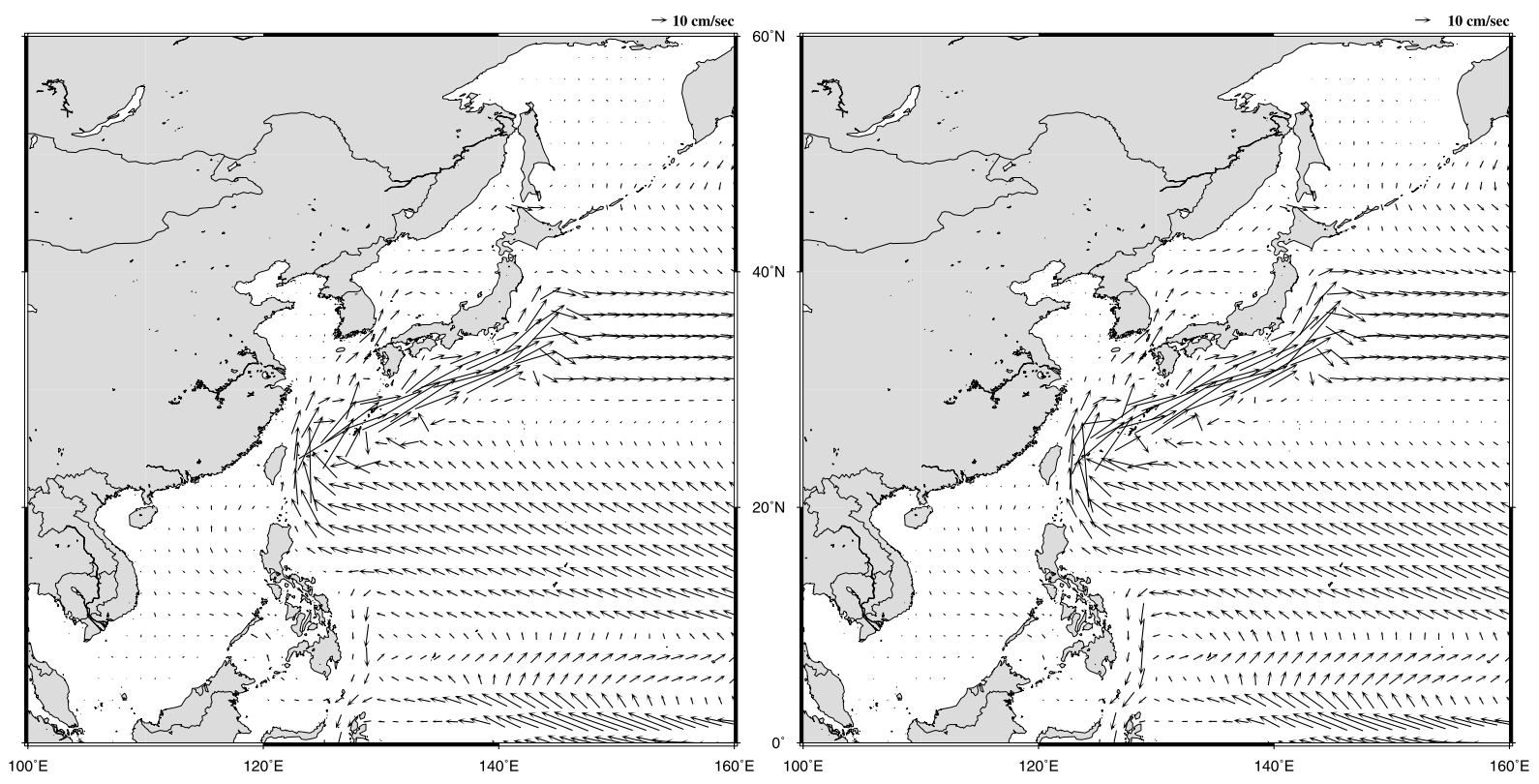

Fig. 13. 10-year annual mean ocean surface currents for a Control Run (left) and for a Increasing Run (right) at year 136 145.

water, is about $19 \mathrm{~cm}$ and $25 \mathrm{~cm}$, respectively, and could be much larger if the contribution of meltwater from continental ice sheets were included. These results are consistent with the results of some models (e.g., HadCM3, and
ECHAM4/OPYC3) from the third assessment report of IPCC (IPCC 2001). Those results show the sea level rise in the Northern Pacific region more than the global average.

In the northwestern Pacific region, surface 


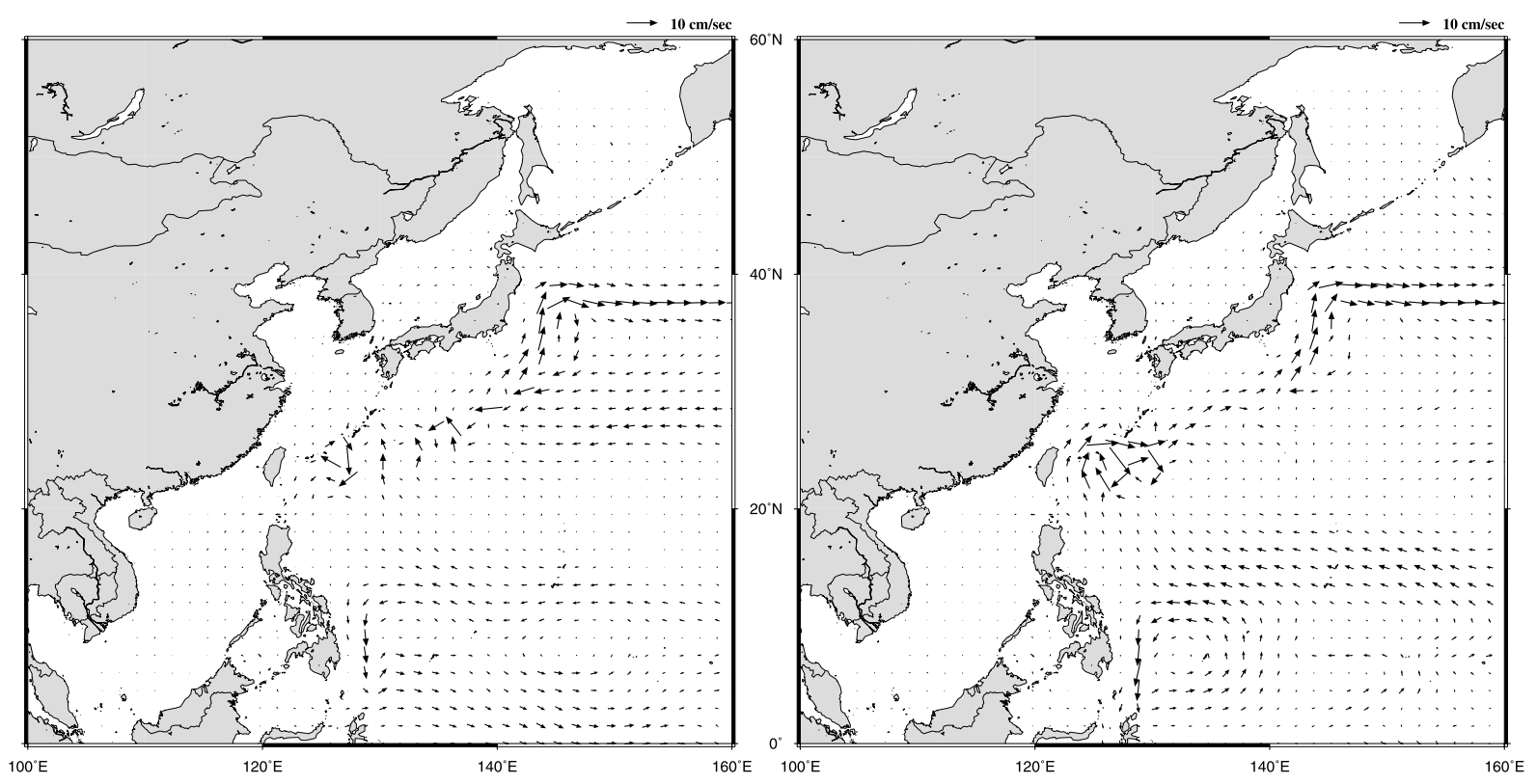

Fig. 14. Changes in decadal mean ocean currents at the surface from a transient $\mathrm{CO}_{2}$ experiments minus control for a doubling (left) and for a quadrupling (right).

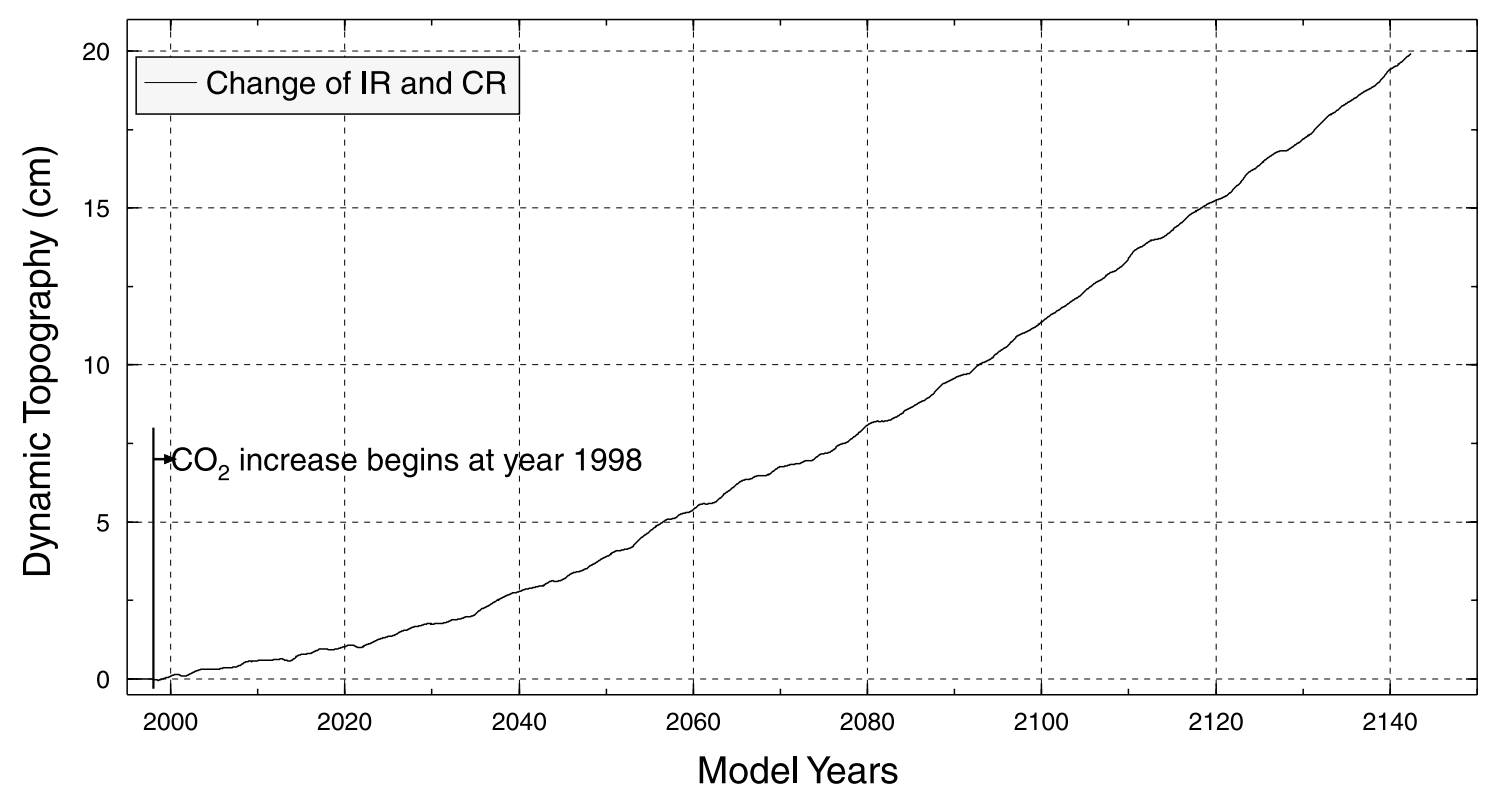

Fig. 15. 12-month running mean change of monthly averaged global mean dynamic topography.

air temperature increase above the continental land mass also is higher than that of the oceans. There are exceptionally large warming, and sea level change, near Kuroshio's separation area. The significant changes in the temperature, salinity and heat exchange in the
Kuroshio separation area are brought about by the northward expansion of the separation area, which is, in turn, brought about by global warming. So, of importance are the meridional expansion of the Kuroshio, and the change of its intensity, not necessarily the mass transport 


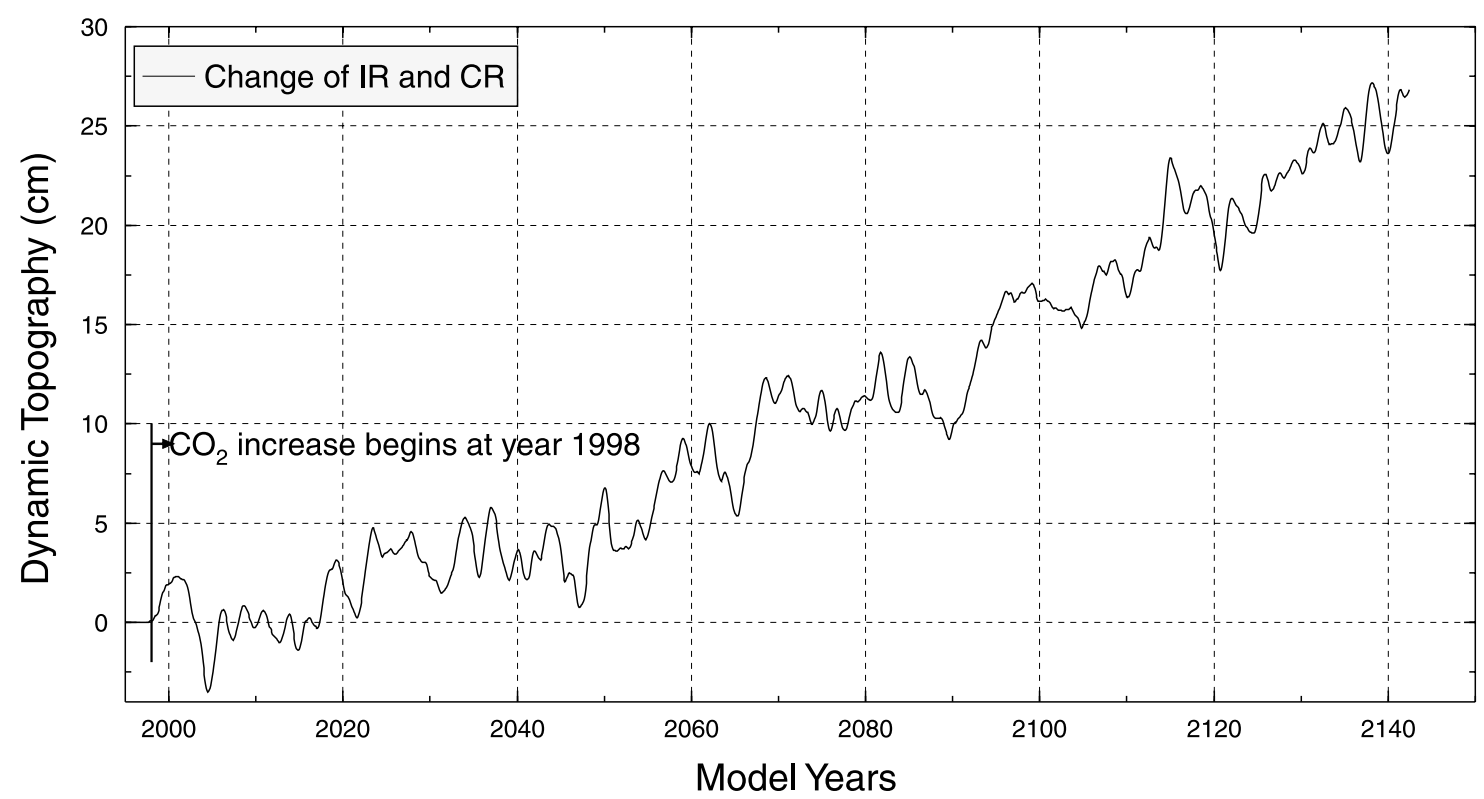

Fig. 16. 12-month running mean change of monthly averaged regional mean dynamic topography in the northwestern Pacific Ocean.

of the western boundary current. The latter also should be the case of the other strong boundary current areas. The changes in the temperature and salinity in the Kuroshio separation region are closely interdependent, and primarily due to the northward expansion of the separation point, which is governed by changes of the global ocean and atmosphere.

Most of the previous experiments have been carried out at low resolution (horizontal grid sizes of $100 \mathrm{~km}$ or greater). The resolution which is finest around the Korean Peninsula as $0.6^{\circ}$ in longitude and $0.9^{\circ}$ in latitude may still not be enough to study the regional responses in the northwestern Pacific Ocean. In reality, changes in sea surface topography will be transmitted by Rossby waves, (and possibly coastal Kelvin waves (Hsieh and Bryan 1996)) and the first baroclinic Rossby radius of deformation in the northern Pacific Ocean is smaller than the model resolution. Inadequacy of the model's resolution to describe fully all of the processes controlling the behavior of the oceans is a present limitation. However, this part heavily depends on the improvement of current computational capabilities. A few studies by CRIEPI (Maruyama et al. 1997; Nakashiki et al. 2001) have also tried to resolve this issue by embedding a $0.5^{\circ}$ submodel of similar region within the global ocean model of the NCAR/ CSM by a one-way process nesting. Their results also showed the meridional extension of the Kuroshio, and its intensity.

Although it has been recognized for a long time that the uptake of heat by the oceans would greatly delay the onset of global warming, the response pattern would be similar to that expected from this study.

\section{Acknowledgments}

The research was performed as a part of first year of second phase (1999 2000) of Natural Hazard Prevention Research (Critical Technology-21) Project, funded by the Ministry of Science and Technology through KISTEP (Korea Institute of Science and Technology Evaluation and Planning), and was supported by the Climate Environment System Research Center sponsored by the SRC program of Korea Science and Engineering Foundation.

\section{References}

Bettge, T.W., J.W. Weatherly, W.M. Washington, D. Pollard, B.P. Briegleb, and W.G. Strand, Jr., 1996: The CSM Sea Ice Model. NCAR Technical Note $N C A R / T N-425+S T R$, National Cen- 
ter for Atmospheric Research, Boulder, Colorado.

Bonan, G.B., 1996: A Land Surface Model (LSM Version 1.0) for Ecological, Hydrological, and Atmospheric Studies: Technical Description and User's Guide. NCAR Technical Note $N C A R / T N-417+S T R$, National Center for Atmospheric Research, Boulder, Colorado.

- 1998: The Land Surface Climatology of the NCAR Land Surface Model Coupled to the NCAR Community Climate Model. J. Climate, 11, 1307-1326.

Boville, B.A. and P.R. Gent, 1998: The NCAR Climate System Model, Version One. J. Climate, 11, 1115-1130.

Briegleb, B.P. and D.H. Bromwich, 1998a: Polar radiation budgets of the NCAR CCM3. J. Climate, 11, 1246-1269.

and $1998 \mathrm{~b}$ : Polar climate simulation of the NCAR CCM3. J. Climate, 11, 12701286.

Bryan, K., 1969: A numerical method for the study of the circulation of the world ocean. J. Comput. Phys., 4, 347-376.

- 1996: The steric component of sea level rise associated with enhanced greenhouse warming: a model study. Clim. Dyn., 12, 545-555.

Chervin, R.M., 1986: Interannual variability and seasonal climate predictability, J. Phys. Oceanogr., 2, 510-514.

Cox, M.D., 1984: A primitive equation, 3-dimensional model of the ocean. GFDL Ocean Group Tech. Rep. No. 1., GFDL/Princeton University, Princeton, NJ.

Cubasch, U., K. Hasselmann, K. Hock, E. MaierReimer, U. Mikolajewicz, B.D. Santer, and R. Sausen, 1992: Time-dependent greenhouse warming computations with a coupled oceanatmosphere model. Clim. Dyn., 8, 55-69.

Dütch, H.U., 1978: Vertical ozone distribution on a global scale. Pure Appl. Geophys., 116, 511529.

Gent, P.R., F.O. Bryan, G. Danabasoglu, S.C. Doney, W.R. Holland, W.G. Large, and J.C. McWilliams, 1998: The NCAR Climate System Model Global Ocean Component. J. Climate, 11, 1287-1306.

Gregory, J.M., 1993: Sea Level Changes under Increasing Atmospheric $\mathrm{CO}_{2}$ in a Transient Coupled Ocean-Atmosphere GCM Experiment. J. Climate, 6, 2247-2262.

Hack, J.J., J.T. Kiehl, and J. Hurrel, 1998: The hydrologic and thermodynamic characteristics of the NCAR CCM3. J. Climate, 11, 1179-1206.

Hsieh, W.W. and K. Bryan, 1996: Redistribution of sea level rise associated with enhanced greenhouse warming: a simple model study. Clim.
Dyn., 12, 535-544.

Hurrel, J., J.J. Hack, B.A. Boville, D. Williamson, and J.T. Kiehl, 1998: The dynamical simulation of the NCAR Community Climate Model version 3 (CCM3). J. Climate, 11, 1207-1236.

IPCC, 1996: Climate Change 1995: The Science of Climate Change, J.T. Houghton, L.G. Meira Filho, B.A. Callander, N. Harris, A. Kattenberg, and K. Maskell (eds.). Cambridge Univ. Press, Cambridge, Table 6.3.

- 2001: Climate Change 2001: The Scientific Basis, J.T. Houghton, Y. Ding, D.J. Griggs, M. Noguer, P.J. van der Linden, X. Dai, K. Maskell, and C.A. Johnson (eds.). Cambridge Univ. Press, Cambridge, Figure 11.13, pp. 672.

Keeling, C.D. and T.P. Whorf, 1998: Atmospheric $\mathrm{CO}_{2}$ concentrations (ppmv) derived from in situ air samples collected at Mauna Loa Observatory, Hawaii. Scripps Institution of Oceanography (SIO), University of California, La Jolla, California USA 92093-0220, http:// cdiac.esd.ornl.gov/ndps / ndp001.html.

Kiehl, J.T., J.J. Hack, G.B. Bonan, B.A. Boville, D.L. Williamson, and P.J. Rasch, 1998a: The National Center for Atmospheric Research Community Climate Model: CCM3. J. Climate, 11, 1131-1149.

— - , and J. Hurrel, 1998b: The energy budget of the NCAR Community Climate Model: CCM3. J. Climate, 11, 1151-1178.

Kim, D.-H., 1998: Sea Level Change due to Global Warming in the Northwestern Pacific Ocean, Ph.D. Thesis, Dept. of Civil Engineering, Sungkyunkwan University.

Manabe, S. and R. Stouffer, 1994: Multiple century response of a coupled ocean-atmosphere model to an increase of atmospheric carbon dioxide. $J$. Climate, 7, 5-23.

, R.J. Stouffer, M.J. Spelman, and K. Bryan, 1991: Transient responses of a coupled oceanatmosphere model to gradual changes of atmospheric $\mathrm{CO}_{2}$. Part I: Annual mean response. J. Climate, 4, 785-818.

, M.J. Spelman, and R.J. Stouffer, 1992: Transient response of a coupled ocean-atmosphere model to gradual changes of atmospheric $\mathrm{CO}_{2}$. Part II: Seasonal response. J. Climate, 5, 105126.

Maruyama, K., H. Hirakuchi, J. Tsutsui, N. Nakashiki, S. Kadokura, and M. Kadoyu, 1997: Global Warming Projection for 125 years using NCAR CSM Coupled Model. CRIEPI Report U97034. (in Japanese)

Motoi, T., A. Noda, S. Nakagawa, S. Yukimoto, M. Endo, and H. Ishizaki, 1996: Sea level changes from a transient $\mathrm{CO}_{2}$ experiment using the MRI CGCM. Proc. 1996 Spring Meeting of 
Japan Meteorol. Soc., 35. (in Japanese)

Murphy, J.M. and J.F.B. Mitchell, 1995: Transient response of the Hadley Centre coupled oceanatmosphere model to increasing carbon dioxide. Part II: Spatial and temporal structure of the response. J. Climate, 8, 57-80.

Nakashiki, N., T. Tsubono, and K. Maruyama, 2001: Prediction of the Global Warming in the Ocean around Japan-Application of a Regional Ocean Model. CRIEPI Report U00058. (in Japanese)

Pacanowski, R.C., K. Dixon, and A. Rosati, 1991: The GFDL modular ocean model user's guide. GFDL Ocean Group Tech. Rep. No. 2., GFDL, Princeton, NJ.

- and - 1993: The GFDL modular ocean model user's guide. GFDL Ocean
Group Tech. Rep. No. 2., GFDL, Princeton, NL. Stouffer, R.J. and S. Manabe, 1999: Response of a Coupled Ocean-Atmosphere Model to Increasing Atmospheric Carbon Dioxide: Sensitivity to the Rate of Increase. J. Climate, 12, 22242237.

- - , and K. Bryan, 1989: Interhemispheric asymmetry in climate response to a gradual increase of atmospheric $\mathrm{CO}_{2}$. Nature, 342, 660-662.

Washington, W.M. and G.A. Meehl, 1989: Climate sensitivity due to increased $\mathrm{CO}_{2}$ : Experiments with a coupled atmosphere and ocean general circulation model. Clim. Dyn., 4, 1-38.

Weatherly, J.W., B.P. Briegleb, and W.G. Large, 1998: Sea Ice and Polar Climate in the NCAR CSM. J. Climate, 11, 1472-1486. 